\title{
Perceptions of health workers regarding the occupational health services rendered at Onandjokwe hospital, Namibia
}

\author{
Amukugo HJ, Amakali K * Sipa K \\ School of Nursing and Public Health, Faculty of Health Sciences, University of Namibia, Namibia
}

Received: February 4, 2015

DOI: $10.5430 /$ jha.v4n6p1

\author{
Accepted: April 17, 2015 \\ Online Published: July 27, 2015 \\ URL: http://dx.doi.org/10.5430/jha.v4n6p1
}

\begin{abstract}
Objective: Health care workers are exposed to a variety of health hazards in their daily work. This exposure puts them at risk of acquiring occupational related diseases, including psychological stress, which can lead to mental illness, absenteeism and job dissatisfaction. In view of the potential risks and occupational hazard, a comprehensive health and safety programme for all employees is mandatory to minimize injury among the employees and therefore for the institution to fully harness the potential of its employees. The programme should indicate management goals, objectives and policy implementation, as well as responsibility and accountability for each role player. The aim of this study was to determine the challenges facing health workers regarding the occupational health services (OHS) at Onandjokwe Hospital in Northern Namibia. The objectives of the study were to determine the existing situation relating to the OHS rendered at Onandjokwe Hospital and to explore and describe the perceptions of health workers regarding OHS at the hospital.

Methods: The study employed both quantitative and qualitative methodology that included the use of a checklist for collection of quantitative data on evidences of practice of OHS in different departments of the hospital; interviews and focus group discussions for collection of the data on the workers' perception on OHS in the hospital. Epi-info software version 3.5.1 was used to analyses the quantitative data while Tech's method of qualitative analysis was used for the qualitative data.

Results: The study revealed that the provision of OHS in the hospital was extremely limited. Many key documents guiding the provision of effective OHS were found to be lacking in several hospital departments. Limited training had been conducted and as a result, there was low awareness on OHS among the employees in the hospital. Both management and staff cited lack of key personnel to drive the process as an important impediment to strengthening OHS in the hospital.

Conclusions: The main recommendations that arose from the research include the need for the hospital management to comply with the guidelines on Occupational health, acquire and avail key guiding documents for occupational health practice in all the departments; provision of necessary resources for OHS including OHS staff and implementation of OHS programme to safeguard the health of the employees.
\end{abstract}

Key Words: Occupational safety, Occupational health services, Employer, Employee, Health workers

\section{INTRODUCTION}

\subsection{Background}

According to the Occupational Health and Safety Forum ${ }^{[1]}$ approximately half of the world's population spends most of its time at work. As a result, fair employment and a decent work life are seen as significant social determinants of health and a healthy workforce is basically a prerequisite for productivity and economic development. However, only

*Correspondence: Amakali K; Email: kamakali@unam.na; Address: School of Nursing and Public Health, Faculty of Health Sciences, University of Namibia, Namibia. 
a small proportion of the global workforce has access to Occupational Health Services, primarily for the prevention and control of occupational work-related disease and injuries. In contrary to the precedent proposition, the International Labor organization ${ }^{[1]}$ indicates that there are more than two million work-related fatalities in the world every year. These accidents and injuries occur because of a lack of proper occupational health services, which are needed to minimize occupational health hazards. Subsequently, the Occupational Health and Safety Forum ${ }^{[1]}$ asserts that occupational health service at the workplace is a significant social determinant of health for the workforce and for economic development and as such, it is a prerequisite.

Occupational health services (OHS) is a multidisciplinary programme that has been designed for preventive functions and is responsible for advising employers, workers and their representatives on maintenance of a safe and healthy working environment in order to facilitate optimal wellbeing of the employees in the work environment. ${ }^{[3-5]}$

The key functions of OHS is to perform surveillance on work environmental factors and work practices that affect the health of the workers ${ }^{[6,7]}$ and to create awareness about work-related health risks among employees. ${ }^{[8]}$ Therefore, the literature, indicate that the dynamics in the workplace and the involvement of workers in participatory initiatives regarding occupational health and safety prevent occupational related health problems and as a result there would be job satisfaction among employees. ${ }^{[9,10]}$

The literatures maintain that occupational health and safety is needed in the workplace to minimize occupational health hazards. As a result, it is recommended that OHS should focus on three main areas: the maintenance and promotion of workers' safety, health and working capacity; the improvement of the working environment; and the development of work organization and work cultures to support health and safety. ${ }^{[2,7,11]}$

The key role players for OHS in an organization are: employers, occupational health practitioners and the employees and their representatives. ${ }^{[2]}$ It is expected that a programme for OHS should have all the essential elements of an occupational safety and occupational health promotion, including policy, organization, planning, implementation and evaluation of the occupational safety and health management system.

In line with the presumptions above, the Namibia Ministry of Health and Social Services (MoHSS) is spearheading the implementation of Occupational Health Services programme in all its/her health care facilities, including the Onandjokwe
Hospital with the aim of upholding safety and maintaining the health of employees in health care sectors. ${ }^{[3]}$ However, there seems to be a gap between what the literature suggests and the reality of occupational health practice at Onandjokwe hospital. Moreover, there have been few or no studies exploring the challenges with the implementation of occupational health services programme at Onandjokwe Hospital. This article discussed the challenges regarding the implementation of occupational health services at Onandjokwe hospital.

\subsection{Problem statement}

Onandjokwe hospital is a district hospital in the Oshikoto region, Northwest of Namibia. Onandjokwe is located approximately $750 \mathrm{~km}$ from Windhoek, the Capital of Namibia and is $60 \mathrm{~km}$ from the Angolan border. The hospital serves the district with a catchment population of 147,179 with an annual growth rate of $2.2 \%$.

Despite the existence of an OHS policy in the Ministry of Health and Social Services and its adoption by Onandjokwe Hospital, there has been an increase in the number of reported incidents of occupational health hazards at the hospital. According to the Onandjokwe Hospital Annual Report ${ }^{[12]}$ health workers at the hospital experienced occupational health problems during the report period which include needle prick injuries (20), musculoskeletal disorders (15), abortion (3) and varicose veins (5). Furthermore, 20 of the health workers resigned as a result of stress and burnout. Therefore, it would seem that the systems that should address these occupational related challenges are not well defined and the needs for the safety of health workers were not well explored before the incorporation of the OHS at the health facility. Consequently, this study was conducted on the practice of occupational health and safety at the facility and the perceptions of health workers regarding the OHS in order to recommend possible solutions to mitigate the occupational health challenges that are experienced at the facility.

\subsection{Purpose of the study}

The main purpose of this study was to determine the challenges facing health workers regarding the Occupational Health Services at Onandjokwe Hospital.

\subsection{Objectives of the study}

The objective of this study was of two fold namely to explore the existing occupational health services rendered at Onandjokwe Hospital and to explore and describe the perceptions of the health workers regarding occupational health services at Onandjokwe Hospital. 


\section{Methodology}

A mixed method of quantitative and qualitative was employed. A quantitative approach was used to describe the existing situation of OHS at Onandjokwe Hospital. Secondly a qualitative approach was employed for a systematic exploration and description of the participants' perception of OHS at their workplace. ${ }^{[13]}$ Equally, the study was contextual as it explored the situation of occupational health services at Onandjokwe Hospital and its employees' perceptions towards the service. ${ }^{[14]}$

\subsection{Population}

There were two populations according to the two objectives of the study. The first population comprised of 10 wards and 10 departments for collection of quantitative data on occupational health services at Onandjokwe Hospital. The target population for the second objective was 293 health workers in the hospital for collection of the data on their perception of the occupational health services at the hospital. These included 239 nurses, 20 doctors, 17 laboratory staff, 7 pharmacy staff, 6 X-ray staff, 3 dental staff and 1 physiotherapist.

\subsection{Sample and sampling}

To address the first objective of this study, which was to explore and describe existing situation of the OHS rendered at the hospital, a random sampling of ten departments and wards out of the 20 departments and wards were selected for the purposes of conducting a situation analysis. ${ }^{[15]}$ The inclusion criteria for the first objective were: all wards and department in the hospital.

To address the second objective of the study, which focused on exploring and describing the health workers' perceptions of OHS at Onandjokwe Hospital, a purposive sampling was employed for collection of the data until saturation criteria was reached. ${ }^{[16]}$ To that end, 10 out 20 doctors, 20 out of 239 nurses, 2 out of 6 radiography staff and 1 out 2 social workers and 1 customer care officer participated in the study for collection of qualitative data. The inclusion criteria for the second objective were: workers who had worked in the hospital for more than two years because of their potential exposure to occupational health hazards at the work place; ability to speak English and participants should had agreed to participate on a voluntary basis.

\subsection{Pilot study}

The pilot study of the qualitative data collection instruments to determine whether the interview question was clear, understandable and lead to trustworthy results ${ }^{[17]}$ was conducted on a small group of health workers who did not participate in the main study. The questionnaire for collection of quantitative data was pilot tested on a small group of health care workers and departments to ensure its reliability. Content validity was ensured through the data collection instrument that contains only questions pertaining to the evidences of OHS rendered at the hospital. A random sampling of ten departments and wards out of the 20 departments also ensured validity of the quantitative data while trustworthiness of qualitative data was ensured by the criteria of data saturation.

\subsection{Data collection}

The first category of the data were of quantitative and were collected through a checklist on the availability of a legal and regulatory framework regarding occupational services; availability of policy documents and processes on OHS in the hospital; availability of policy strategies and practices as well as the availability of staff welfare facilities in the workplace as evidences of practice of OHS in the departments and wards of the hospital. Quantitative data were randomly collected until the sample size was reached. The second category of the data were qualitative on health workers' perception on Occupational Health Services at the hospital and were collected through individual interviews, field notes and three focus group discussions. ${ }^{[18]}$ Qualitative data were purposefully collected until the data saturation was reached. Three focus group discussions of different categories of health care workers were held (of registered nurse, enrolled nurse and enrolled midwives; of a radiography assistant, social workers and a customer care officer; of doctors from various departments, including medicine, pediatrics, casualty, and gynecology and obstetrics). The following open-ended question was posed to the participant to allow the participant to describe their view on the occupational health services: Tell me about your view and experiences of occupational health services at your workplace at Onandjokwe hospital! The focus group discussions were conducted until data saturation was obtained. The data from the interviews and focus group discussion were tape recorded and field notes were kept. ${ }^{[19]}$

Ethical principles of justice and autonomy and beneficence were observed. In that regard, the study was conducted, after the study was approved by the Post-Graduate Study Committee of the University of Namibia. The permission to collect the data from the hospital was granted by the Research and Ethical Committee of the Ministry of Health and Social Services and the Regional Director of Health in Oshikoto. The purpose of the study was explained to the participants. Participation was voluntarily and confidentiality was maintained with regard to dissemination of the findings. The benefits that employees can gain from the improvement of the occupational health services at their workplace were explained. 


\subsection{Data analysis}

The, Epi-info software version 3.5.1 was used to process the quantitative data by the researcher and a statistician. Descriptive statistics were used to describe the variables.

The qualitative data from the interviews and group discussions were analyzed using Tesch's eight steps of quantitative data analysis. ${ }^{[20]}$

\section{Results}

The findings from the quantitative data are provided in descriptive statistics. Narrative descriptions of the findings from the qualitative data are provided under the themes and sub-themes. In the next session, findings on quantitative variables are presented, followed by the findings on qualitative data.

\subsection{Availability of a legal and regulatory framework}

An inquiry into the availability of legal framework in various departments indicates that the Presidential Proclamation No. 10 of the Labour Act 1992 was not available in any of the departments assessed. All the departments (100\%) were found to have a copy of the Labour Act of 2004. The Government Notice No. 156 "Regulations Relating to Health and Safety at Work" was only available in one (10\%) department, while the Employees Compensation Act, 1941, was not found in any of the departments. The HIV Code on Employment was available in one department, that is, $10 \%$ of departments, and was not available in nine (90\%). The Public Health Act, 1919, was also found in one department $(10 \%)$ only. However, the Affirmative Action (Employment) Act, 1998, was found to be available in eight (80\%) departments, with it being unavailable in two (20\%) (see Figure 1).

\subsection{Availability of policy documents and processes}

Regarding a policy framework, the National Occupational Health Policy (NOHP) for OHS, which governs OHS in the country, was only available in one $(10 \%)$ of the departments and was not available in nine (90\%) of the departments. Training and education on risk mitigation regarding OHS was reported to be provided in nine $(90 \%)$ of the departments, while a safe working environment was reported by eight $(80 \%)$ of the departments, with two $(20 \%)$ departments reporting otherwise. Equity in the workplace was reported in nine $(90 \%)$ of the departments while one $(10 \%)$ stated that there was no equity in the workplace. Figure 2 shows the findings regarding policy and processes at the hospital based on the departments assessed.

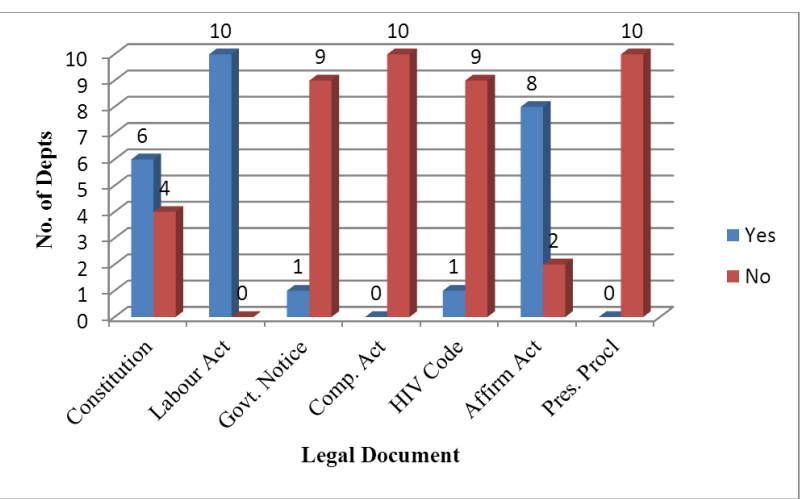

Figure 1. The availability of legal framework in various departments $(n=10)$

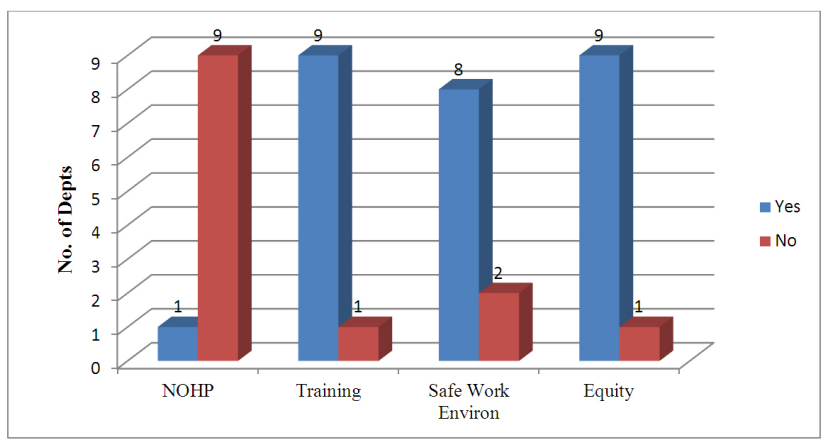

Figure 2. Policy document and processes $(\mathrm{n}=10)$

\subsection{Policy strategies and practices}

Under this point, OHS practice indicators, Documentation of occupational health strategies, Availability of OHS and staff and Availability of occupational hygiene and medicine services were assessed, the findings of which are described below.

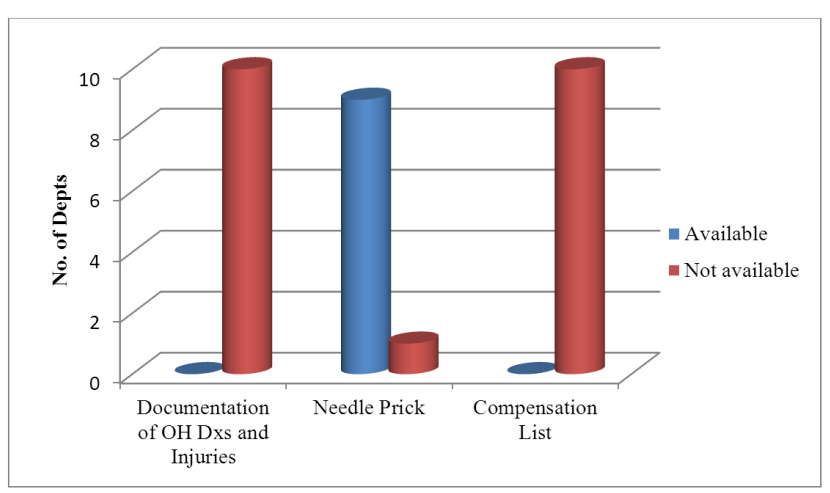

Figure 3. OHS practice indicators $(\mathrm{n}=10)$

Policy strategies relating to practice indicators showed that documentation on types and causes of occupational diseases and injuries experienced at the hospital was not available in all the departments. However, documentation on needle 
prick injuries was available in nine (90\%) of the departments while not available in one (10\%). A list of the type of compensation given for occupational disease and injury was not available in any of the departments assessed.

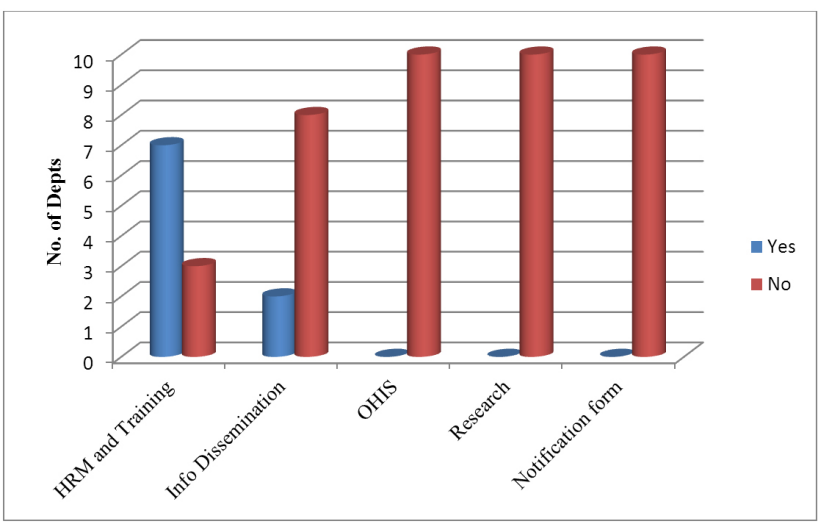

Figure 4. Documentation of occupational health strategies $(\mathrm{n}=10)$

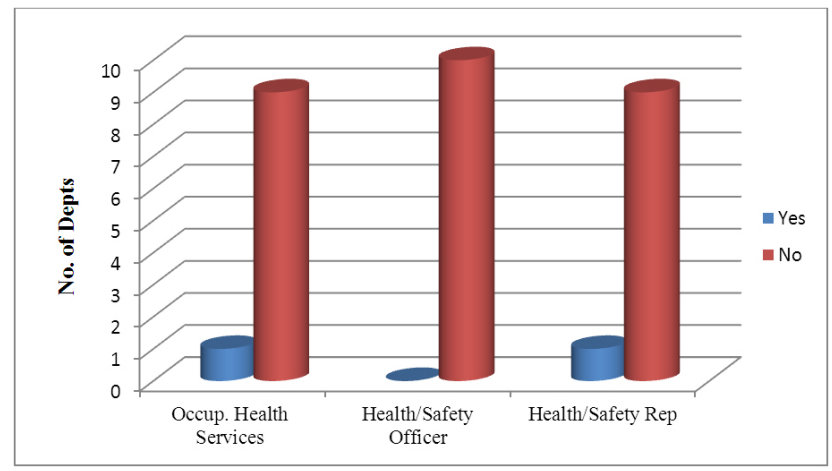

Figure 5. Availability of OHS and staff $(n=10)$

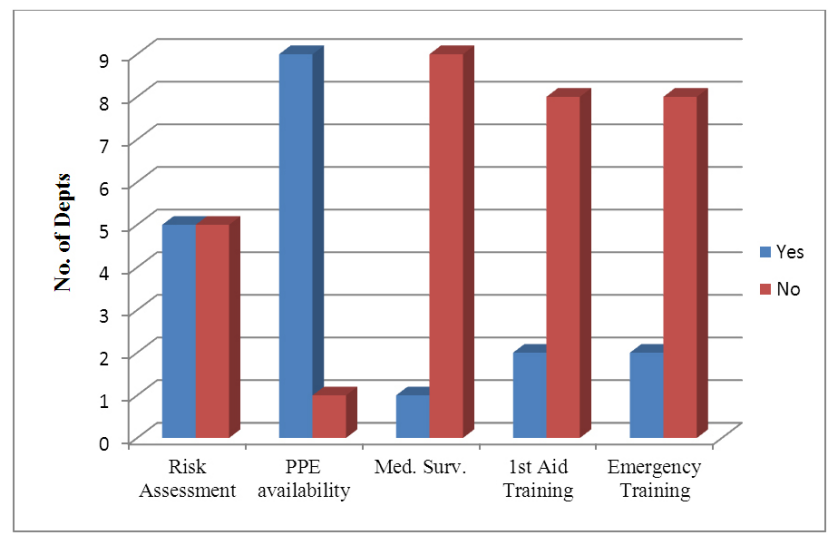

Figure 6. Availability of occupational hygiene and medicine services $(n=10)$

Documentation on the occupational health strategies relating to human resources management and training was available in seven $(70 \%)$ of the departments but unavailable in three (30\%), while the dissemination of OHS information was reported as being carried out by only two (20\%) of the departments. An occupational health information system was not available in any of the departments assessed. Neither any research has been done in relation to OHS nor had any notification of occupational disease forms been completed. Occupational hygiene and medicine provision as well as a risk assessment policy was only available in five (50\%) of the departments. However, personal protective equipment (PPE) and a staff training policy were available in nine $(90 \%)$ of the departments although unavailable in one (10\%). Emergency training and first aid were provided in eight $(80 \%)$ of the departments, while medical surveillance at the workplace was provided only in one department which represents just $10 \%$ of the selected departments.

The availability of staff for the implementation of OHS was low. The practice of medical surveillance at the workplace was reported to be provided only in one department (10\%). Moreover, a health and safety representative was available in just one department, which represents $10 \%$ of the departments surveyed as summarized in Figures 3-6.

\subsection{Staff welfare and welfare facilities in the workplace}

In terms of staff welfare and facilities in the workplace, the results indicated that eight $(80 \%)$ of the departments had a well-ventilated working environment that was well lit and clean, while only two $(20 \%)$ of the departments were found to have poor ventilation, poor lighting and of poor hygiene. All the departments had clean and sanitary toilets (100\%), but restrooms were found in only five $(50 \%)$ of the departments. However, $90 \%$ (9) of the departments had safe drinking water close to the workplace with only one (10\%) of the departments not having safe drinking water. Hand washing facilities were provided in six $(60 \%)$ of the departments, which is similar to the finding for heating and cooling appliances, which were also found in only six $(60 \%)$. These findings on staff welfare and facilities are presented in Figure 7.

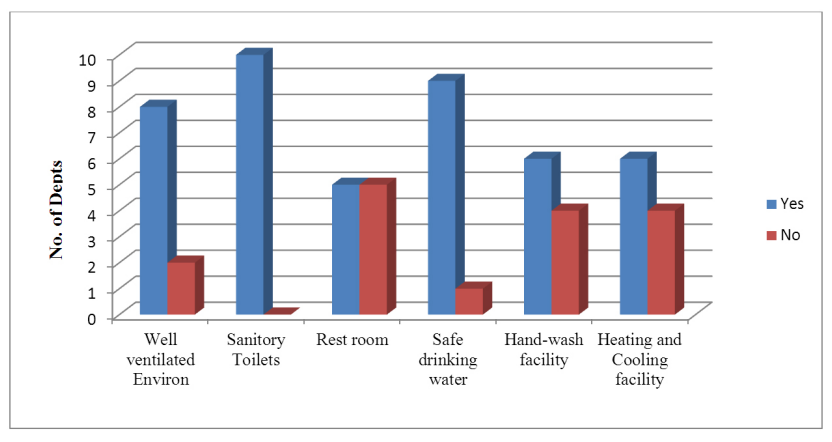

Figure 7. Availability of staff welfare and welfare facilities $(n=10)$ 
The second category of the data was the qualitative data that were collected through the individual interviews and focus group discussions on the participants' perception of the occupational health services at Onandjokwe hospital. Tape-recorded interview were transcribed. Qualitative data analysis was employed, using Tesch's eight steps of quanti- tative data analysis. ${ }^{[21]}$ Main ideas were coded and themes were identified.

Three (3) main themes and sixteen (16) sub-themes that emerged from the analysis of the data from the interviews and focus group discussions are summarized in the Table 1.

Table 1. Themes and sub-themes

\begin{tabular}{|c|c|}
\hline Themes & Sub-themes \\
\hline $\begin{array}{l}\text { Theme 1: Health workers' } \\
\text { perceptions of the availability } \\
\text { of occupational health } \\
\text { support. }\end{array}$ & $\begin{array}{l}\text { - Unavailability of legal framework and standards and policy for the implementation of OHS and protective } \\
\text { equipment to enhance occupational health support. } \\
\text { - Lack of Medical surveillance for health workers at the facility. } \\
\text { - Lack of health education to staff members regarding occupational health safety, and the use of protective } \\
\text { measures. } \\
\text { - Lack of implementation of National Occupational Health at the facility. }\end{array}$ \\
\hline $\begin{array}{l}\text { Theme 2: Health workers’ } \\
\text { perceptions regarding OHS } \\
\text { challenges. }\end{array}$ & $\begin{array}{l}\text { - Lack of guidance from MOHSS regarding OHS. } \\
\text { - Lack of resources such as material, financial and human to facilitate the implementation of the OHS. } \\
\text { - Health workers' fear of stigma and discrimination by members of the public by being in the same queue } \\
\text { for the treatment. } \\
\text { - High staff turnover contributes to the non-implementation of OHS. } \\
\text { - Unavailability of workers compensation for occupational injuries. } \\
\text { - No comprehensive OHS. }\end{array}$ \\
\hline $\begin{array}{l}\text { Theme 3: Health workers' } \\
\text { perception of knowledge on } \\
\text { OHS. }\end{array}$ & $\begin{array}{l}\text { - Lack of knowledge on the use of protective equipment provided. } \\
\text { - Lack of knowledge of health workers' charter and rights. } \\
\text { - Lack of knowledge and awareness of occupational health risk. } \\
\text { - No clear procedure for reporting work-related injuries and grievances. } \\
\text { - Lack of knowledge about the existing occupational health services. }\end{array}$ \\
\hline
\end{tabular}

\subsubsection{Lack of guidance from the Ministry of Health and Social Services regarding occupational health ser- vices}

The participants stated that the employers are ignorant of their legal responsibilities and duties to provide OHS at the hospital. This revelation concurs with a report by the World Health Organization which states that effective implementation of OHS in Namibia is challenged by the inadequate enforcement of legislation because employers and employees are ignorant of their legal responsibilities and duties. ${ }^{[6]} \mathrm{Cer}-$ tain of the participants highlighted some of the managerial challenges that influence OHS negatively:

"No guidance from Ministry of Health and Social Services regarding occupational health services."

"There is reluctance in government to strengthen the implementation of occupational health services."

"There is lack of capacity in strategic office, to strengthen the implementation of occupational health services." "There is lack of knowledge and poor support effort from management."

"There is ignorance of management level to implement occupational health programme."

\subsubsection{Lack of resources such as material, financial and human to facilitate the implementation of occupa- tional health services}

The participants highlighted that some of the health workers did not complete hepatitis B immunisation due to the unavailability of resources such as immunization against communicable disease. The participants also stated that often, protective provided were not sufficient for all health workers. Consequently they were forced by circumstances to share protective clothing such as boots and gowns. The following quotes from the participants are evidence to that claim:

"I did not complete the dose for hepatitis $B$, because vaccines were not enough and now I don't know if I have to restart the vaccination or not, we use to ask several times if the immunisation for hepatitis $B$ is available at PHC but the response was none; I was told to go to private practitioner to complete the vaccination."

"I need specific clinic for the health workers consisting of doctors and nurses working there full time, even in event of needle prick a person may be attended to at once; we need quick services." 
"Health workers are provided with gowns but they are shared from one health worker to another."

"Sometimes health workers are exposed to occupation hazards because they operate without protective measures such as gloves."

"No specific department for Occupational Health Services due to organisation structure."

"The infrastructures are going beyond replacement, walls are falling down, not enough light, and this can contribute to hazard at workplace that may affect the client or health worker."

In addition to lack of material resources, the majority of the respondents indicated a lack of human resources for the implementation of Occupational Health Services at the hospital, as evidenced by the following responses from the participants:

"There is no OHS representative." "We need appointment of occupational health committee-active one, health and safety representative in each unit."

"We are having a problem at our hospital, no people to implement such programme."

"I think although protective measures are provided there is a need for focal person to control how protective measures are used and monitor health workers' needs."

"As a health worker, I am expecting at least to have a (private consultation for health worker) clinic for the health workers, where there is a nurse, doctors and social workers."

"As a health worker, I am expecting at least to have certain examination to be done; annual check up to be done to determine health or illness status of the health workers, blood test, the $x$-ray and dental services."

"Health workers are exposed to occupational hazards like prolonged standing, no assessment done; at least we need three months assessment or periodical assessment.”

A lack of resources for the implementation of Occupational Health Services translates into lack of necessary knowledge for the appropriate use of occupational health protective measure by health care workers as described in the next session.

\subsubsection{Lack of knowledge on the use of the protective equip- ment provided}

The study participants further stated that they required medical surveillance to determine their health and illness status and whether they have acquired an occupational disease. Here is what some of the participants in the study stated regarding the problem:

Published by Sciedu Press
"We are having a problem at our hospital. There is no money to implement such programme."

"There are financial constraints that prevent health workers to undergo medical surveillance."

"Posts for occupational health services are not advertised since there is no budget for it."

"The financial problem is the barrier to occupational health services implementation."

\subsubsection{Lack of workers compensation for occupational in- jury}

The study findings revealed that there was no workplace compensation available to compensate health workers who sustain occupational health related injuries. The following statements from one of the focus group discussions indicated the need for health workers to be compensated after having acquired occupational injuries or diseases as compensation would secure their future.

"We need to be compensated in order to support our family."

"No compensation made on occupational injury."

"Nothing can be done when you got injury at workplace regarding our future."

"Compensation is a must; we need it to support our family; just imagine, you are working in TB ward and you acquire $M D R$, or pricked by needles and acquire HIV, we need to be compensated in order to support our family."

\subsubsection{Lack of implementation of the National Occupa- tional Health Services at the facility}

The participants indicated reluctance from the hospital management to implement the National Occupational Health Policy at the institution. The following quotes from the participants are evidences to that:

"To me, the policy is not implemented. I am not satisfied; I was not oriented toward occupational health services."

"The way I see it is that, the policy is available but not implemented; there is no provision for occupational health services. Because people are too busy to implement it, some departments need to be prioritized."

"We are expecting OHS to be provided according to the policy, but now we cannot give details since we don't know the content of the policy and we need to see the policy first in order to know what is required." "I do not know what services is stipulated in the policy."

"I need to know the policy content so that I will know my right and my obligation." 
3.4.6 Lack of comprehensive occupational health services The data from both focus group discussion and in-depth interviews with the various staff categories of the health workers also implied lack of comprehensive occupational health services as can be verified from the following assertions:

"As we are mothers and bearing children then our babies stay long time without breastfeeding, we need a place in the hospital to breastfeed our baby, hospital must provide the place and health workers."

"I think an occupational health service is necessary because health workers need to be attended to separately not in the same queue with general public patients."

\subsubsection{Lack of knowledge on health workers' Charter of Rights}

Many of the participants in the focus group discussions indicated that they needed to know their rights as entrenched in the health workers' Charter of Rights. Participants also proposed that an awareness of health workers' right should be raised among the general public as the latter displays a negative perceptions and attitudes toward health workers. Here is a sample of what some of the participants said in this regard:

"I think health workers need a bill of rights like the patient charter."

"Health workers are also having social problem that need to be attended to in order to provide a quality services. Therefore if their rights are provided, then they will be a happy at work."

"I am also thinking that a charter is needed to stipulate rules and regulations to be followed by patients to respect health workers."

"Health worker charter is very much needed. If this happen it will stipulate health workers right/ need like right to treatment and right to be respected as well as to express the inner feeling; charter need to be that patient/community can understand health workers and behave well because health workers are also having problem to be addressed, for the community to know the right of the health workers." "I never seen health workers bill of right but I think it is needed!"

\subsubsection{Lack of knowledge and awareness of occupational health risks among health care workers}

Lack of knowledge and awareness of health risk are of the issues which were indicated by the participants. The focus group discussions with various categories of health workers revealed the following perceptions:

"We are lacking knowledge when come to occupational health."
"Health workers are not aware of the occupational health risk."

"We also need information and health education on selfprotection against infection but only little information provided; we need more and more information even weekly."

"We need refresher course on Occupational Health Services by management."

\subsubsection{Lack of clear procedure for reporting work-related injuries and grievances}

The participants claimed that there was no known standard procedure to be followed by the health workers after they acquired occupational injuries, diseases or experience dissatisfaction. Hence, they were not aware of their rights, responsibilities and obligations. Consequently, during the focus group discussions and the in-depth interviews, the participants stated their opinions as follows:

"I am having occupational health problem after medical surveillance but I don't know where to go."

"Problems are that there is no guideline on occupational health services."

"If am in casualty, I report to casualty chief, if I am in ward I report to PMO, but I experience problem and I didn't report it because I don't know where to report; there is no clear procedure."

"People are having problem and questions regarding Occupational Health Services and occupational hazard but they do not know where to report during the weekend."

\subsubsection{Lack of knowledge about the existing occupational health services}

In conclusion, the findings revealed that workers at Onandjokwe hospital do not have access to occupational health services at the health facility. The administrative system of the hospital seems complacent as regard the safety and health of its employers. This is evident in the following quotes from the participants:

"I don't know if an occupational health service is implemented in this hospital."

"I am not aware if an occupational health service is available in Onandjokwe hospital."

"I haven't seen any occupational health services information provided to health workers in this setting regarding their health benefit."

"I heard occupational health services somewhere but not at this institution, not existing in the hospital."

"I don't have any information regarding occupational health 
services available in this organization. I never heard anything in my life."

"As radiographer I use to undergone medical surveillance on annual basis but I do know the reason why it has been carried out."

\subsection{Validity and reliability and Trustworthiness}

In order to ensure validity of the quantitative data, two types of validity were considered. An instrument for collection of quantitative data represented all the components of the variables to be measured. ${ }^{[22]}$ This was ensured by having the tool reviewed by the researcher supervisors and statistician and by conducting a pilot study, after which the content of the instrument was refined. In order to ensure face validity, the tools was reviewed by peers and research supervisor to ensure that the tools were meant to address the variables of interest. [23]

In objective two, credibility, transferability, conformability and dependability, were maintained in order to ensure trustworthiness. These criteria or principles are important in guiding the researcher in maintaining the true value, applicability, consistency and neutrality of the research process and the resultant findings. ${ }^{[13,18]}$

\section{Discussion}

The aim of the study was to determine the existing situation relating to the occupational health services rendered at Onandjokwe Hospital and to describe the health workers' perceptions regarding the occupational health services at Onandjokwe Hospital. The results of this study are discussed in line with the study objectives. In the first session, the findings of the quantitative data as related to the first objective are discussed.

\subsection{Legal and regulatory framework}

The findings have highlighted a serious shortage of the necessary documents of legal and regulatory framework for Occupational health services across many departments of the hospital. Key documents such as the Government Notice relating to health and safety and the National Occupational Health Policy were found in one department only, while copies of the Employees Compensation Act and the Presidential Proclamation Act of No. 10 of the Labour Act 1992 were not found in any of the departments assessed. These are documents that managers, supervisors and staff need to rely on in planning, implementing and monitoring, as well evaluating, the efficiency and effectiveness of the OHS in the hospital. Legal documents guarantee the health, safety and welfare of employees in the workplace. As a result, they guarantee and facilitate the improvement of work environment

Published by Sciedu Press for the national economic active population. ${ }^{[24]}$

\subsection{Policy documents and processes}

As in the case above, the findings revealed lack of policy documents and processes for Occupational Health Services at the hospital. In that regards, the National Occupational Health Policy on OHS was not available in most of the departments. Therefore, the majority of the health workers did not have access to it. This revelation is in contrary to the suggestions by Work Safe Victoria ${ }^{[25]}$ which indicates that policy procedures should be available, communicated to and understood by all employees as an important part of implementation of Occupational Health Services. However, training and education on risk mitigation in OHS, a safe working environment and equity in the workplace were provided in some of the departments.

\subsection{Policy strategies and practices}

In terms of policy strategies and practices, the findings revealed that documentation on the types and causes of occupational diseases and injuries experienced at the hospital as well as the lists and types of any compensation given for occupational diseases and injuries were not available in any of the departments. No research had been done in relation to OHS in any department, nor had forms been completed on the notification of occupational diseases. Nevertheless, the literature concurs that the key strategic principles of international and national occupational health and safety policies are the avoidance of hazards, safe technology, optimization of working conditions, integration of production, health and safety activities. ${ }^{[26,27]}$ A policy on compensation for work-related injuries was also unavailable. However, documentation on needle prick injuries was available in all departments.

Documentation on occupational health strategies for human resources management and training was also virtually nonexistent. Information on OHS was available in a few departments while the Occupational Health Information System was not available in any. According to Occupational Health Services ${ }^{[24]}$ human resources play a vital role to control, monitor and evaluate the implementation and enforcement of the relevant legislations relating to occupational health issues pertinent in the workplaces to meet national and international conventions and treaties obligations. The maintenance and promotion of employees' health in general, by protection of employees against any occupational health related hazards or injuries cannot be overemphasized.

\subsection{Occupational hygiene and medicine services}

Occupational hygiene and medicine risk assessment on person and policy was available in one department only. Although personal protective equipment was available in all the 
departments, there was no training of personnel, and policy on the use of the equipment was not available. Only first aid and emergency training were provided. Furthermore, medical surveillance in the workplace was provided for the X-ray department only. To implement OHS, a well-planned strategy must be implemented, and this would include annual planning of the number of employees to go for medical examinations per month and their outcome-based projections; a facility for examination or evaluation, for instance a staff clinic; a record-keeping system that is accessible and sustainable; and annual reports to management. Problem areas identified during surveillance should be reported and recommendations should be made to mitigate the risks identified. $^{[27]}$

\subsection{Occupational health services}

The study revealed a glaring lack of OHS at Onandjokwe Hospital, with only two departments offering some semblance of OHS (kitchen and X-ray department). The OHS provided in the workplace covered only by ten percent. In addition, there was no health and safety officer available in many of the departments, except in one department. The proponent of occupational health practice argue that OHS can be utilized not only to prevent injuries and absenteeism, but to contribute to all health workers' knowledge and their practical attainment of connections between working conditions and health. ${ }^{[28]}$

\subsection{Staff welfare and facilities}

Staff welfare was considered and facilities provided in many of the departments as many were found to have a wellventilated working environment, and well-lit and clean working areas. All the departments had clean, sanitary toilets. Restrooms were provided in half of the departments assessed and most of the departments were found to have safe drinking water close to the workplace. Hand wash facilities were provided in many departments, and $50 \%$ of the departments had heating and cooling appliances. The Health and Safety Authority ${ }^{[29]}$ stated that the workplace facilities needed for staff include staff restaurants, first aid and occupational health services. It is important to make provision for workers to prepare their foods and to allow workers to take their longer meal breaks away from their workstation by providing them with a restroom. The data from both focus group discussion and in-depth interviews with the various staff categories of the health workers also implied lack of comprehensive occupational health services, specifically a lack of provision of paid time off for the purposes of breastfeeding. The Health and Safety Authority ${ }^{[29]}$ emphasizes the rights of the breastfeeding mother at workplace as stipulated by the Maternity Protection. This Act advocates that the breastfeeding mothers are entitled, under legislation, to paid time off for the purposes of breastfeeding or else expressing milk in the workplace, where facilities are provided by the employer or a reduction in working hours with full pay to facilitate breastfeeding. In addition to the revelations from the quantitative data, qualitative data provide appalling disclosures pertaining to Occupational health Services at Onandjokwe Hospital. In the next session, findings from the qualitative data are therefore discussed.

The second objective was to describe and explore the perceptions of the health workers regarding occupational health Services at Onandjokwe Hospital. In depth interviews and focus group discussions were conducted among health workers to achieve this objective. Themes and subtheme were derived from the qualitative data, the discussion of which is presented in the next sessions.

\section{Theme 1: Health workers' perceptions of the availability of occupational health support}

Health workers who participated in this study reflected a positive perception of OHS at the hospital as demonstrated by the participants' heightened desire for the occupational health services at the facility and substantiated by the sub-themes.

To that end, the findings revealed lack of the implementation of legal and regulatory framework, policy strategies and practice for occupational health services at Onandjokwe hospital. As a result, there was a glaring lack of occupational services at the facility. The majority of the respondents indicated that there was no OHS provided to health workers. An adult fitness walking programmers that had been provided as part of wellness activities was taking place outside the hospital within the community. In exemption to the annual x-ray, a full scale of medical surveillance for the health care workers was not available. Equally, there was no policy strategy for compensation of workers in case of work related injuries. Therefore, there was no clear procedure for reporting workrelated injuries and grievances for the health care workers. This is complemented by a reported lack of health workers' knowledge of workers' charter and rights and a lack of awareness and knowledge of occupational health risks among health care workers.

Protective measures that can guarantee health workers' safety in the workplace such as protective clothes, safety, surgical face masks, N95 masks, gloves, hepatitis B immunization, safe injection information, air conditioning and fans, were reported to be either lacking or there was a lack of knowledge on the use thereof by health care workers. Lack of knowledge on the use of protective measures is substantiated by the reported lack of health education to the employees on 
the use of protective measures to protect themselves against infection and health hazards. These deviant findings are contradictory to the assertion by the proponents of occupational health services who assert that either a code of practice for occupational health services must be available as part of health and safety issues in the workplace ${ }^{[30]}$ or there is a need to have occupational health support workers within the occupational health setting to execute agreed health screening and surveillance of the workers. ${ }^{[30]}$ As regard the employees' behaviors, the literature maintains that there must be a process in place to educate staff in the use and maintenance of personal protective equipment, and that such equipment should be available and accessible. ${ }^{[30,31]}$ Equally, education and training are crucial components of safe, healthy working environments. Therefore, education on the use of protective measures must be provided on a regular basis while workers' competency in the usage of the protective measures be maintained at the facility. ${ }^{[32]}$

\section{Theme 2: Health workers' negative perceptions of OHS challenges}

Negative perceptions in this study refer to the fact that the health workers who participated in the study declined the availability of OHS in the hospital. During the study, participants listed the managerial challenges that influence OHS negatively supported by several sub-themes related to lack of guidance from the MoHSS for the implementation of OHS, lack of resources such as material, financial and human to facilitate the implementation of the OHS, high staff turnover which contributes to the non-implementation of OHS, health workers reluctance to use OHS in fear of stigma and discrimination by members of the public by being in the same queue for the treatment, unavailability of workers compensation for occupational injuries, lack of implementation of National Occupational Health policy and a lack of comprehensive OHS. Furthermore, health care worker participants indicated that the hospital has no focal person for OHS to supervise how protective measures are used or to answer their questions about work-related problems or to ensure infrastructure for a safe working place. As a result, the participants stated that some of the infrastructure was beyond repair and poses an occupational hazard in the workplace. This revelation concurs with the reports on institutional occupational health practice elsewhere that state that environmental and occupational health services in many African countries are undermined by a lack of priority setting, poorly designed workplace safety and therefore rendering environmental protection policies below the standard. ${ }^{[26,33]}$

Theme 3: Health workers' perceptions of knowledge on occupational health services

Published by Sciedu Press
The majority of the respondents indicated that OHS does not exist in the organization; furthermore, some were not aware of whether or not the services or the policy were available because they did not have any knowledge of OHS or the occupational health hazards in the hospital. A few of the respondents said that OHS have been provided but people were not aware of it because they were not well informed; moreover, the policies and guidelines were available but had not been implemented.

Complete medical surveillance was not available at the hospital apart from the annual X-ray for the staff. This situation is substantiated by the sub-themes of: lack of knowledge of health workers' charter and rights, lack of knowledge and awareness of occupational health risk, lack of clear procedure for reporting work-related injuries and grievances, lack of knowledge on the use of protective equipment provided and lack of knowledge about the existing occupational health services. As regard the Charter of Right for the employees and in advocacy for respect, dignity of health care workers ${ }^{[34]}$ health workers at Onandjokwwe hospital need a Health Workers Charter of Right for the patients to acknowledge the rights of health workers and therefore to protect health care workers against the psychosocial hazards by the clients of health services.

\subsection{Implications for the occupational health services}

The results of the study depict poor state of occupational health services at the Onandjokwe hospital. The situation calls for the hospital management to implement the legal and regulatory framework and policy strategies for facilitation of the implementation of occupational health services at the health care facility. As the literature advocates the implementation of the occupational health services would minimize occupational health hazards, prevent occupational related health problems, promote the health of health workers, prevent staff turnover, and in return increases productivity of the institution. ${ }^{[5,29]}$

Moreover, the guidelines from the Occupational Health Services report ${ }^{[24]}$ has emphasized that it is mandatory that all employees be subjected to health surveillance which possibly will include pre-placement examinations, transfer examinations, periodic examinations and examinations to identify a baseline for the candidate's health against which any future changes can be measured. Therefore, possible risk of deterioration in health status which might be caused by the job process and work environment can be discovered. Equally, the provision of workers' compensation for work related injuries cannot be overemphasized because a certain work related injury may compromise the workers' health for life. In conclusion, the findings on the status of occupational health 
services at Onandjokwe hospital also has implications to other workplaces, both nationally and globally: Workplaces ought to comply with the mandates of the International Labor Organization, ${ }^{[2]}$ which advocates for the provision of sound occupational health services at workplaces, to prevent occupational related health hazard, thus safeguarding employees' potentials while promoting productivity among employees.

\subsection{Limitation}

The qualitative data were limited to the information that the participants have provided in the interviews and focus group discussion. The participants might have reservations in providing the information about their perception of the state of occupational health services at the facility. Additionally, the study was conducted in only one district hospital. There- fore the findings may not necessary be generalizable to other hospital in the country.

\section{Conclusions}

The study revealed an extremely limited provision of occupational health services at Onandjokwe hospital and many key documents guiding the provision of effective occupational health services were found lacking in several departments of the hospital. There was low awareness on occupational health services among employees in the hospital and only limited training has been conducted in the hospital. Both management and staff cited lack of key personnel to drive the process as an important impediment to the implementation and strengthening of OHS in the hospital.

\section{REFERENCES}

[1] Occupational Health and Safety Forum. International forum on occupational health and safety: Policies, profile and services. Finland: Hanassari Cultural Center; 2011.

[2] International Labour Organizations (ILO). Code of practice on workplace violence in services sector and measures to combat this phenomenon. Geneva: International Labour Office; 2004.

[3] Ministry of Health and Social Services (MOHSS). National Occupational Health Policy. Republic of Namibia: Windhoek; 2006.

[4] World Health Organization (WHO). Global strategy on occupational health for all: The way to health work. Switzerland: Geneva; 1995.

[5] Rantanen J, Lamberg M, Taskinen H. Good occupational health practice: A guide for planning and follow up of occupational health services: Finland: Institute of Occupational Health. 2004.

[6] World Health Organization (WHO). OHS in Namibia. Presentation at the WHO/TNO/Dutch Government Congress, Connecting Health and Labour. 2012.

[7] World Health Organization (WHO). Good practice in occupational health services: Contribution to workplace health. Copenhagen: WHO Regional Office for Europe; 2002.

[8] Hammer W, Price D. Occupational \& industrial safety health management and engineering ( $5^{\text {th }}$ ed.). United State of America: Prentice Hall; 2004.

[9] Abdullah ACN, Spickett JT, Rumchev KB, et al. Assessing employees' perceptions on health and safety management in public hospitals. International Review of Business Research Papers. 2009; 5(4): 54-72.

[10] Granzow K, Theberge N. On the line: Worker democracy and struggle over occupational health and safety. Canada: Sage; 2008.

[11] Somavia J. Guideline on occupational safety and health management system. Geneva: International Labour Office; 2001.

[12] Onandjokwe Annual Report. Onandjokwe Hospital Annual Report for 2011. Oshikoto Region: Onandjokwe Lutheran Medical Services; 2011.

[13] Babbie E, Mouton J. Practice of social research. Cape Town: Oxford University Press; 2009.

[14] Holtzblatt K, Wendell J, Wood S. Rapid contextual design: A how-to guide to key technologies for user-centered design. San Francisco: Morgan Kaufman; 2005.
[15] Burns N, Groves SK. The practice of nursing research: Appraisal, synthesis and generation of evidence ( $6^{\text {th }}$ ed.). USA: Saunders; 2009.

[16] Brink H. Fundamental of research methodology for health care professionals ( $2^{\text {nd }}$ ed.). Cape Town: Juta; 2010.

[17] De Vos AS, Strydom H, Fouche CB, et al. Research at grass roots: For the social sciences and human services professional. Pretoria: Van Schaik; 2006.

[18] Krueger DA, Casey MC. Focus group: A practical guide for applied research ( $3^{r d}$ ed.). California: Sage; 2000.

[19] Punch KT. Introduction to Social Research: Qualitative and Quantitative Approach. London: Sage; 2009.

[20] Ulin PR, Robinson ET, Tolley EE, et al. Qualitative methods: A field guide for applied research in sexual and reproductive health. USA: FHI; 2002.

[21] Van der Walt C, Van Rensburg G. Fundamentals of research methodology for health. 2006.

[22] Sim J, Wright C. Research in Health care: concepts, Designs and Methods, Cheltenham: Stanley Thomas (publisher) Ltd; 2000.

[23] Occupational Health Services. Occupational Health Services for health care workers in the National Health Services of South Africa A guideline booklet. South Africa: Department of Health; 2003.

[24] Work Safe Victoria. Getting started with workplace health and safety: An introduction to workplace health and safety policies, procedures and evaluation. Victoria Government: Work Cover Authority; 2001.

[25] Constantinidis TC, Vagka E, Dallidou P, et al. Occupational health and safety of personnel handling chemotherapeutic agents in Greek hospitals. Greece: Institution of Athens; 2010.

[26] Hamzoui EE. Occupational Health and Safety Management System. Ethiopia: Institute of Medicine; 2007.

[27] Medical Surveillance. Medical surveillance definition. 2013. [Retrieved December 27, 2013]. Available from: http://www. ikhamb icare.com/surveillance.html

[28] Schmidt L, Sjöström J, Antonsson AB. How can OHS in Sweden contribute to work ability? Sweden: Swedish Environmental Research Institute; 2012.

[29] Health and Safety Authority. Pregnant at work - Frequently asked questions. 2013. [Retrieved on August 5, 2013]. Available from: http://www.hsa.ie/eng/Workplace_Health/SensitiveR isk_Groups/Pregnant_at_Work_FAQ_Responses/.html 
[30] Sikorski, Swerhun, Lawrie, et al. Protecting health care workers from infectious diseases: A Self-Assessment Tool. Public Services Health and Safety Association. 2012.

[31] Work Cover. Occupational health consultant. Australia: Edtex Australia; 2002.

[32] Alli BO. Principles of occupational health and safety (2nd ed.). Geneva: International Labour Office; 2008.
[33] Bilia M, Manyele SV. Chemical management and occupational health in Tanzania: Challenges and strategies for improvements. AfrNewslett on Occupation Health and Safety. 2003; 13: 56-59.

[34] Macquarie University Hospital. The Australian Charter of Health Care Rights: Aguide for patients, consumers, carers \& families. 2013. [Retrieved January 04, 2014]. Available from: http://www.muh.org.au/patientinfo/theaustrali ancharterofhealthcarerights.aspx 